\title{
Cellular Prion Protein and Sexual Dimorphic Areas in Rodents. Correlates with Alzheimer Disease
}

\author{
Mar Cuadrado-Tejedor ${ }^{1}$, Ana Irujo ${ }^{1 *}$, Beatriz Paternain ${ }^{1}$, María Jesús Madrid ${ }^{2,3}$, José Luis Velayos ${ }^{1,2}$ \\ ${ }^{1}$ Department of Anatomy, Faculty of Medicine, University of Navarra, Pamplona, Spain; ${ }^{2}$ IMMA (Institute of Applied Molecular \\ Medicine), Faculty of Medicine, University San Pablo CEU, Boadilla dl Monte, Madrid, Spain; ${ }^{3}$ Department of Basic Medical Sci- \\ ences, University San Pablo-CEU, Boadilla dl Monte, Madrid, Spain. \\ E-mail: *airujo@unav.es
}

Received October $6^{\text {th }}, 2011$; revised November $20^{\text {th }}, 2011$; accepted November $29^{\text {th }}, 2011$.

\begin{abstract}
The cellular prion protein (PrPC) expression was analyzed by western-blot in the rat, in two different dimorphic brain areas such as the anterior hypothalamic and the preoptic areas. In both cases, the PrPC expression was increased in males, implying a sexual dimorphism for the PrPC protein. The study was also made in other two brain areas, frontal cortex and hyppocampus (a clearly dimorphic area); in this case, mice of different ages of both sexes were used. In both brain areas analyzed, although the PrPC expression was increased with age until the adult age (38 weeks), it was decreased in aged animals (56 weeks) in both sexes. The PrPC expression in mouse hippocampus was predominant in males in comparison to females. Moreover, the non-glycosylated band was increased with age and this increase was parallel with the increase observed for the glycolsylated band. The non-glycosylated band increases more in aged females. Altogether, these data suggest that PrP in rodents, in the brain areas analyzed, has a dimorphism role. As we discuss in the present study and in relation to previous studies of our group these data could be extrapolated to humans (specially in Alzhemer disease cases).
\end{abstract}

Keywords: Prion Protein (PrPc), Dimorphic, Alzheimer, Hippocampus

\section{Introduction}

The cortical and subcortical regions in mammals, which belong mainly to the limbic system, develop a sexual dimorphism.

The hypothalamus is a crucial structure within the limbic system. It deals with the regulation of sexual function, particularly via the hypothalamic-hypophyseal systems; from which stem the sexually dimorphic structures of the hypothalamus [1-3].

In the female rat, it has been observed that before birth the dendrites of the neurones of the supraoptic nucleus are isolated from each other as astrocytic prolongations are interposed between them: during lactation, the neurones and the dendrites show close apposition, thus enabling adequate synaptic transmission [4].

The preoptic area, which is usually included within the hypothalamus, is a typical sexually dimorphic nucleus $(\mathrm{SDN}]$, as has been observed in various experimental animals [5-7].

The anterior hypothalamus is considered to be sexually dimorphic, especially with regard to the interstitial nuclei of the human anterior hypothalamus (NIHA1, 2, 3 and 4) $[8,9]$.

The ventromedial nucleus of the hypothalamus is also considered to be sexually dimorphic, oestrogen dependant, having marked plasticity and a greater synaptic density in men than in women [10].

The suprachiasmatic nucleus is not clearly sexually dimorphic, although it does present connections with some dimorphic nuclei, such as the preoptic area. The anterior periventricular nucleus is larger in women than in men.

If we consider non hypothalamic structures, the vomeronasal organ of rodents is sexually dimorphic [11]. The olfactory system is important for reproductive aspects in many animals.

The cerebral amygdala is activated differently in male 
animals, compared to females [12-14]. The bed nucleus of the stria terminalis (BSTc), the size of which increases with age, is larger in men than in women [15].

The size of the hippocampus is larger in females in the vast majority of animals; in birds, its size depends on the tasks carried out by each sex (building nests, searching for food, feeding the young) [16].

The neocortex, which is particularly developed in the human species, presents certain dimorphic characteristics [3,17-19]. And the bulbocavernosus nucleus of the spinal cord [20] is larger in male animals than in females.

Cellular prion protein (PrPC) a glycoprotein with a molecular weight of 33-35 kDa found in various organs, is especially abundant in the central nervous system [21, 22]. PrPC is attributed with an implication in adhesion phenomena, neuroprotection and cellular signalling. In 2010 Velayos et al. [2] observed the diverse localisation of PrPC in the central nervous system of various mammals, always with a predominance in the more rostral areas of the central nervous system.

The relationship between the PrPC and physiopathological mechanisms of Alzheimer's disease (AD) is well understood [23-29]. On our part, we have observed a particular behaviour of $\operatorname{PrPC}$ in brains with AD. There is less expression of $\operatorname{PrPC}$ in patients with $\mathrm{AD}$ than in control cases, furthermore in $\mathrm{AD}$, the non-glycosylated band is larger than the di- and monoglycosylated bands in Western blots of PrPC [30]. To this it should be added that according to statistical studies, $\mathrm{AD}$ is found to be more frequent in women than in men.

For this reason the aim of this research is to study the differences in both sexes of the levels of PrPC in the preoptic area and suprachiasmatic regions, clearly dimorphic structures, as well as in the hippocampus which although it is not strictly considered to be dimorphic, is however an important structure with regard to memory processes. We have also analyzed in some cases the frontal cortex, an area which is particularly active in cognitive processes. Thus, the main goal of the present study, is determine whether PrPC has a distinct functional significance in the two sexes.

\section{Material and Methods}

\subsection{Animals}

Rats: groups of rats of 9-weeks-old, males and females respectively, were used $(n=6)$.

Mice: three groups of 3 different ages, males and females respectively, were used $(\mathrm{n}=3)$.

Group 1: young mice (6 weeks-old)

Group 2: adult mice (38 weeks-old)

Group 3: old mice (56 weeks-old)

Rats samples of the preoptic area and the anterior hy- pothalamic area were analyzed. Mice samples of the frontal cortex and hippocampus were analyzed.

The work was carried out in accordance with the 1975 Helsinki Declaration and approved by the Ethics Committee of the Faculty of Medicine of the University of Navarra.

\subsection{Production of Protein Extracts}

Brains were rapidly removed and the preoptic area and the anterior hypothalamic areas from the rats were rapidly removed. In the case of the mice, the hippocampus and prefrontal cortex were rapidly dissected according to standard procedures and frozen in dry ice. For proteins determination, total tissue homogenates were obtained by homogenizing the hippocampus in ice-cold RIPA buffer and centrifuged at $14.000 \times \mathrm{g} 4^{\circ} \mathrm{C}$ for $20 \mathrm{~min}$.

\subsection{Immunoblotting}

The proteins were separated using $15 \%$ acrylamide gels and were transferred to a nitrocellulose membrane, and incubated with the PrPC antibody mAb 6H4, from Prionics (dilution: 1:6000). Once the adequate conditions had been established, the corresponding measurements using densitometry were taken.

\subsection{Statistical Analysis}

Each biochemical assay was repeated 3 times and the data were analyzed using Student's t-test. The significance level was set at $* \mathrm{p} \leq 0.05,{ }^{* *} \mathrm{p} \leq 0.01$.

\section{Results}

Analysing the results of the Western blot from the rats (Figure 1), it was observed that the level of PrPC is larger in males than in females, in the preoptic area and in the anterior hypothalamic areas.

In the case of the mice (Figures 2-6), taken as a whole, it can be seen that the level of PrPC increases with age with regard to the frontal cortex, in both sexes up to the age of 38 weeks, decreasing in level in those of more advanced age. The level corresponding to the non- glycosylated band increases with age, as compared to the other bands, showing a very similar pattern in both males and females (Figure 2).

With regard to the hippocampus (Figure 3), differences can be seen between males and females; in both cases (males and females) there is a decrease in the levels of PrPC in old-mice. However, while in male mice, PrPC levels are similar in young and adult mice, in the case of female mice, at the adult age there is a marked increase in the levels of PrPC when compared to the group of young animals. This increase is also observed in the case of the non-glycosylated band.

In the groups of young (Figure 4) and adult (Figure 5) 

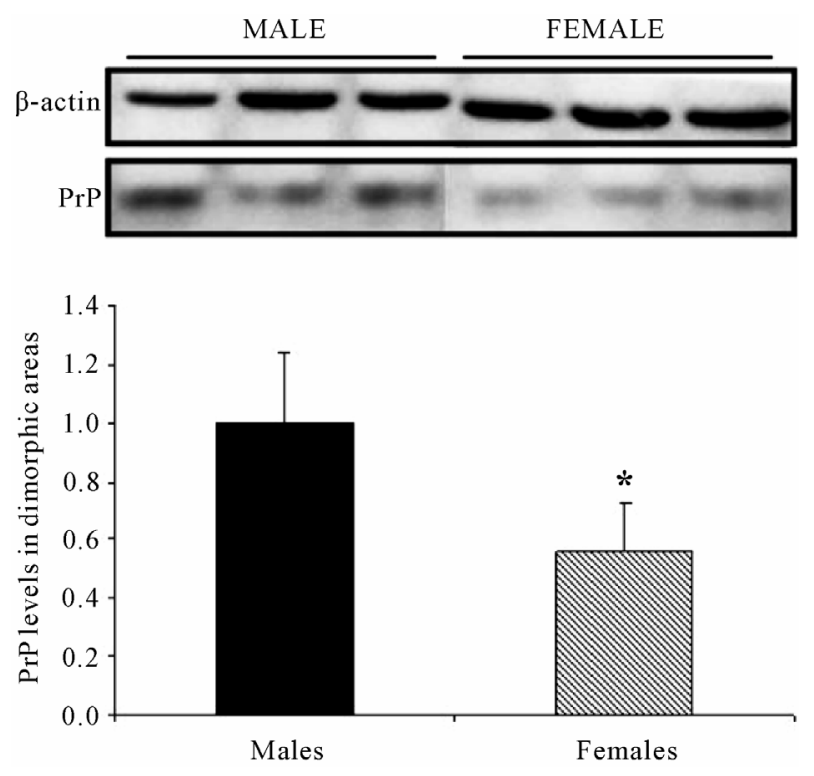

Figure 1. PrPC levels in dimorphic areas are decreased in female compared to male-mice. Western blot of the anterior hypothalamic and preoptic areas, from 6 - 9 week-old, male and female rats. The level of PrPC is larger in male than in female rats.

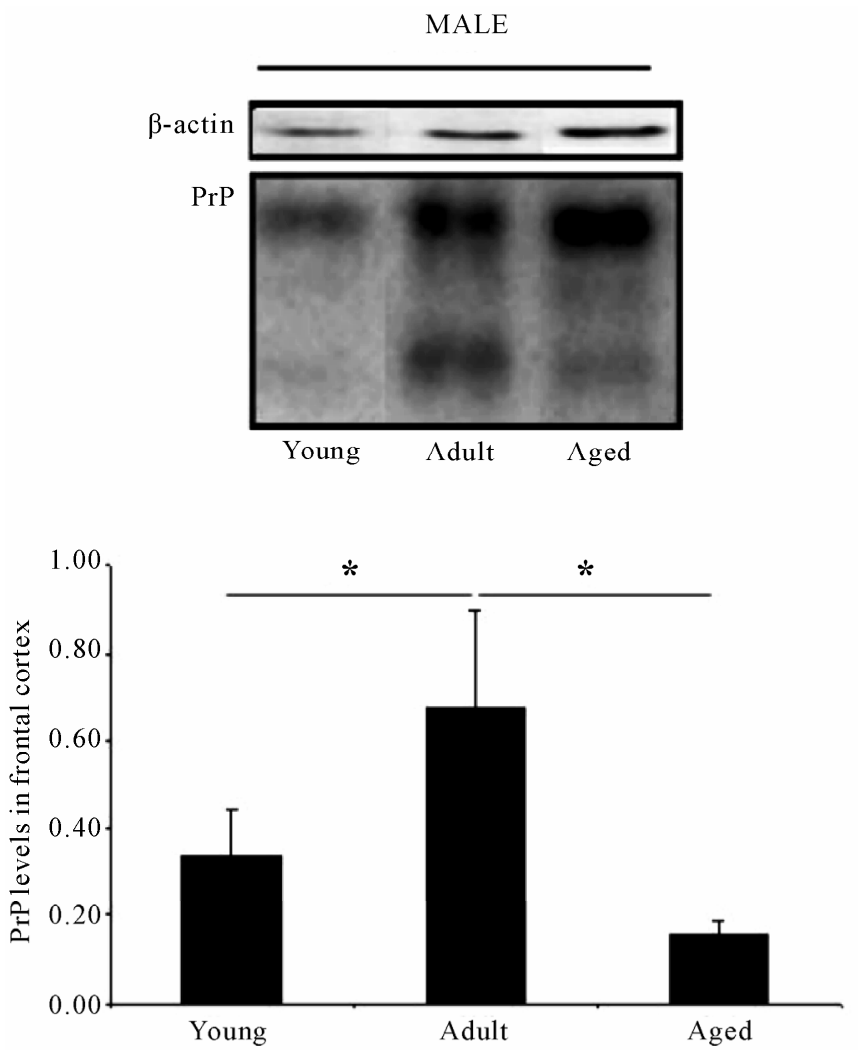

animals, no changes in PrPC levels were found in frontal cortex and/or the hippocampus between both sexes. However, in the group of old-mice, comparing both sexes, while the frontal cortex seems to have a larger level of PrPC in the case of female animals, no changes were detected with regard to the hippocampus (Figure 6).

Thus, globally, it seems that, the expression of PrPC is decreased in old-animals. Related to the different ages analyzed, it has been observed that PrPC changes in the hippocampus of female mice between young and adultmice (with a marked increase in the case of adult-mice) but no changes are detected in male mice. In the case of the frontal cortex the changes between the different ages analyzed are similar for males and females mice.

\section{Discussion}

$\mathrm{SDN}$, of the preoptic area, is the hypothalamic nucleus which is clearly sexually dimorphic [5-7,31,32]. It was first described as such in rats by Gorki et al. [33,34] at the end of the seventies in the last century, as a nucleus which was several times larger in the male rat than in the female. The masculinisation of this structure starts during the foetal stage [35]. Prenatal androgens interfere with

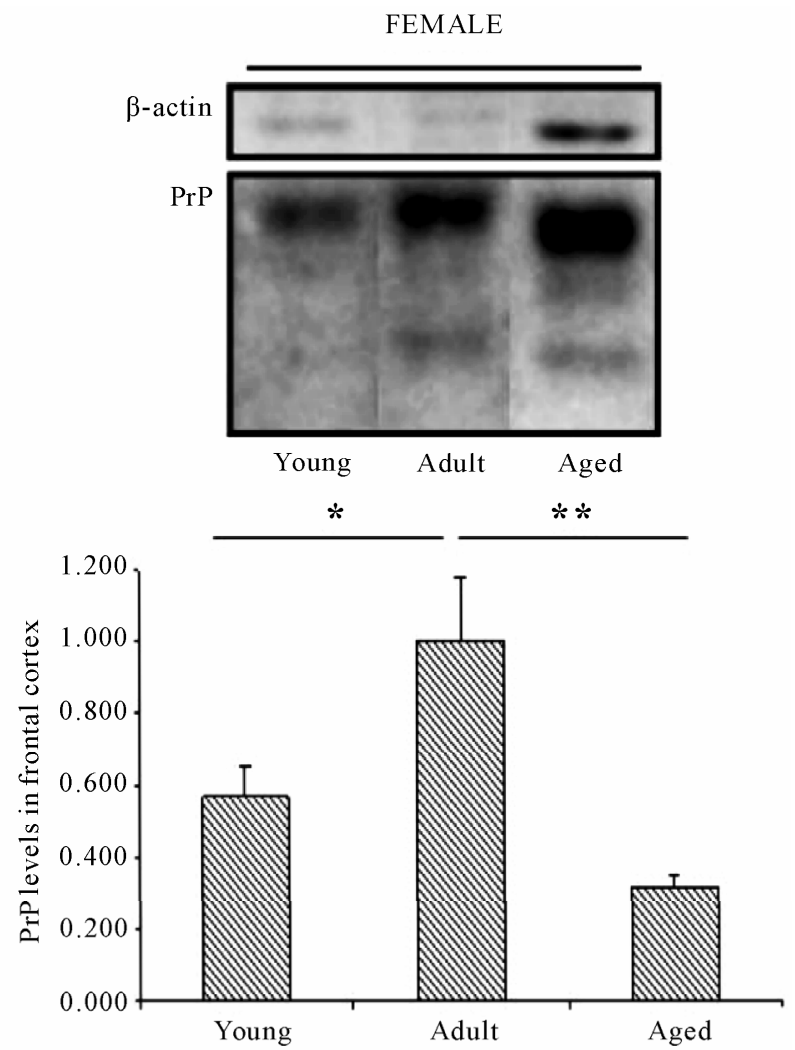

Figure 2. PrPC levels in prefrontal cortex are increased in mice of the adult age compared to young-mice but are decreased in aged mice. Representative western blot bands from prefrontal cortex tissues of mice of 3 different ages: young: 6 weeks, adult: 38 weeks and old: 56 weeks. The histograms represent the quantification of the immunochemically reactive bands in the western blot. $n=4$ in each group. ${ }^{*} \mathrm{p}<0.05 * * \mathrm{p}<0.01$. 

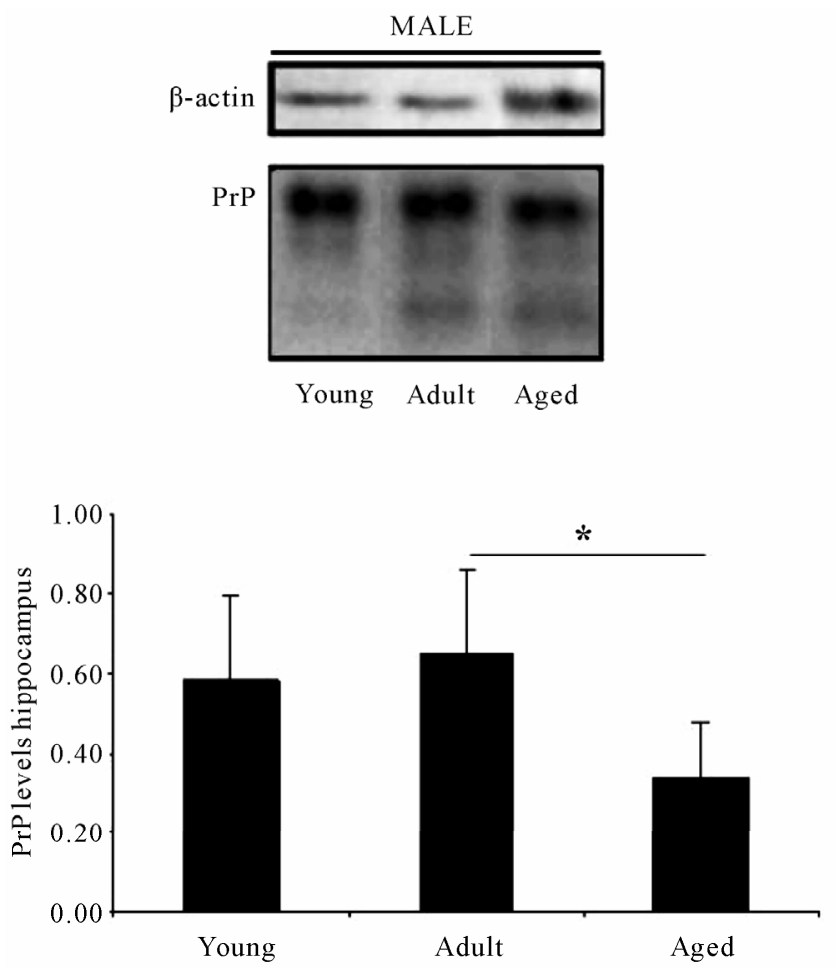
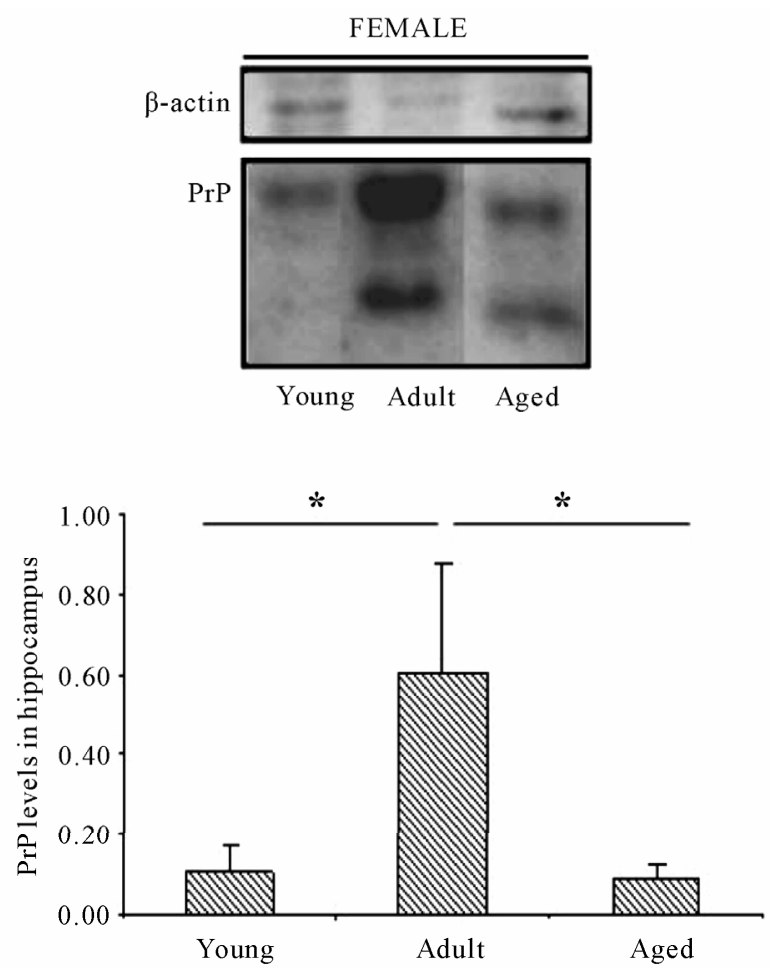

Figure 3. PrPC levels in the hippocampus are increased in female mice in the adult age compared to young-mice. In both sexes PrPC levels decrease in aged mice. Representative western blot bands from prefrontal cortex tissues of mice of 3 different ages: young: 6 weeks, adult: 38 weeks and old: 56 weeks. The histograms represent the quantification of the immunochemically reactive bands in the western blot. $\mathrm{p}<0.05$.
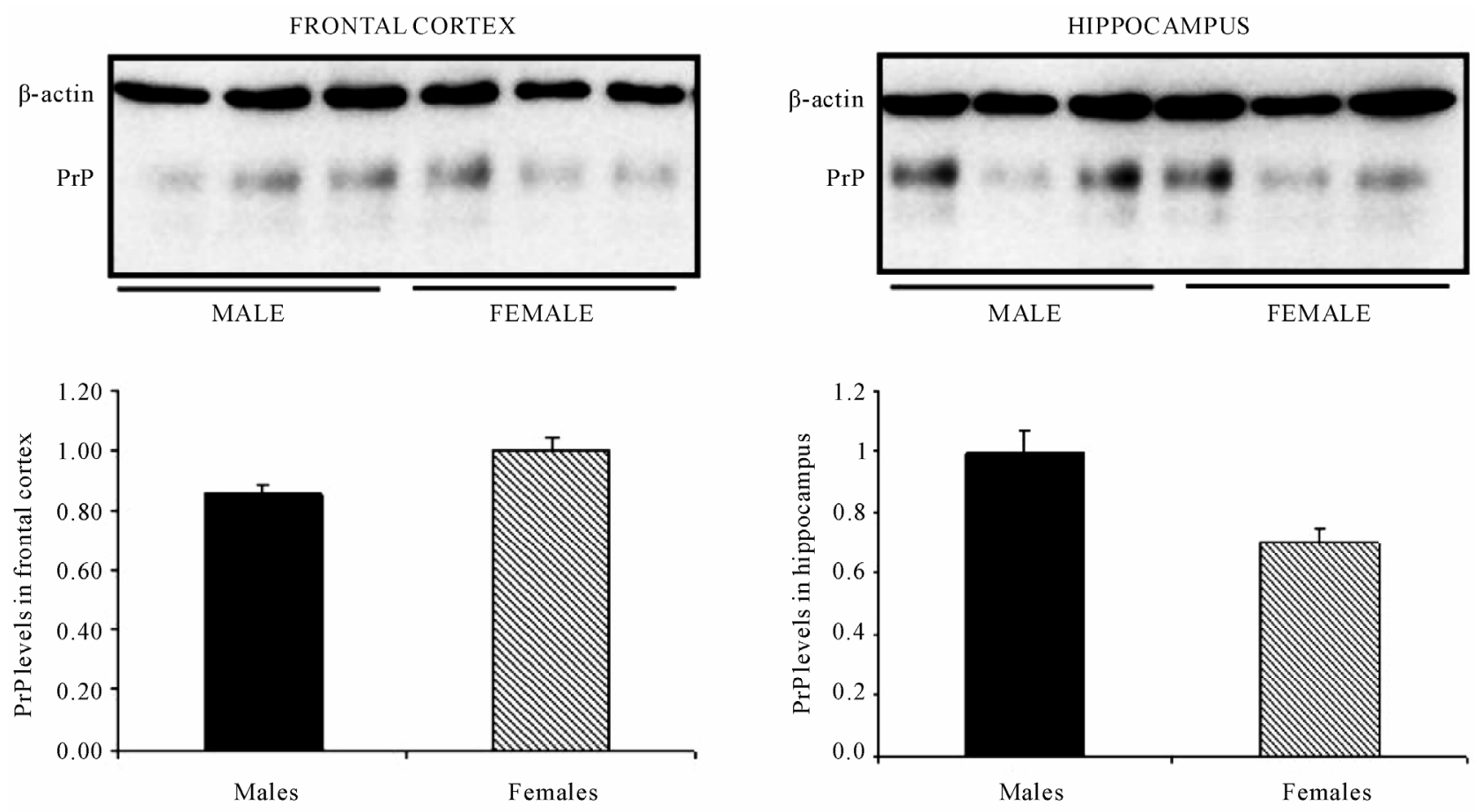

Figure 4. In young-mice, no changes in PrPC levels were found in frontal cortex and/or the hippocampus between both sexes. Representative western blot bands from prefrontal cortex or hippocampal tissue of young-mice (6 weeks). The histograms represent the quantification of the immunochemically reactive bands in the western blot. 
FRONTAL CORTEX
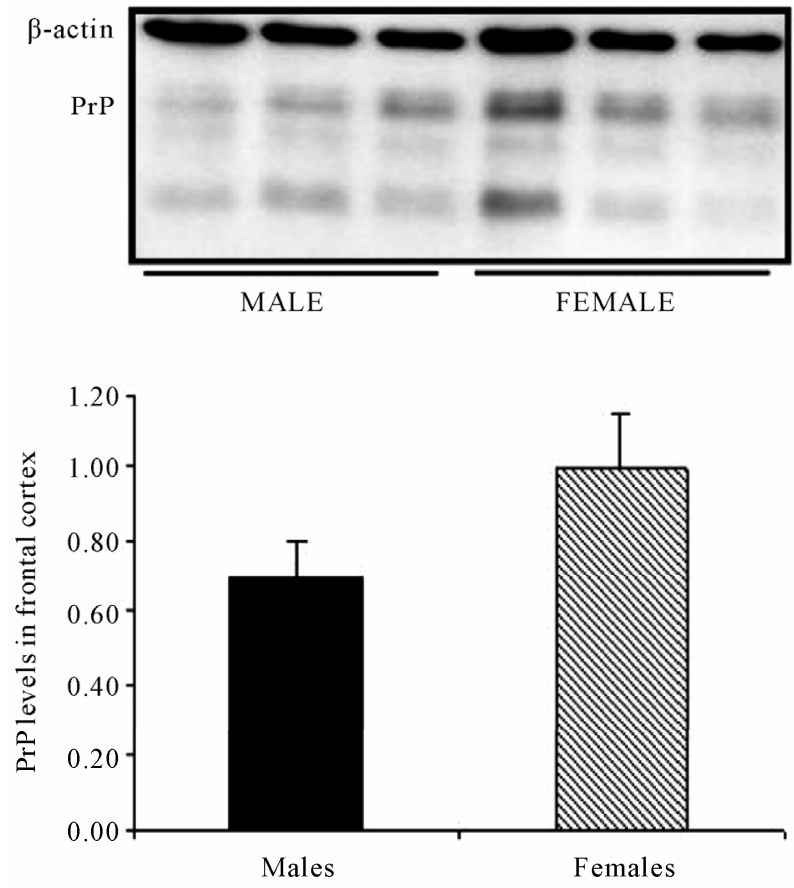

HIPPOCAMPUS
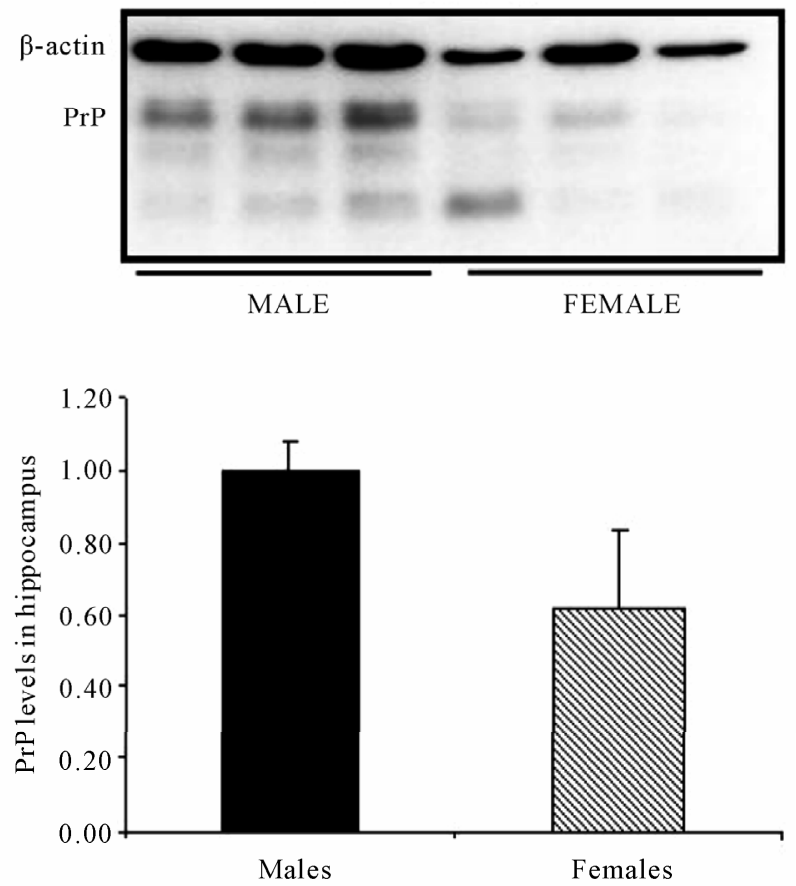

Figure 5. In adult mice, no changes in PrPC levels were found in frontal cortex and/or the hippocampus between both sexes. Representative western blot bands from prefrontal cortex or hippocampal tissue of adult mice (38 weeks). The histograms represent the quantification of the immunochemically reactive bands in the western blot.
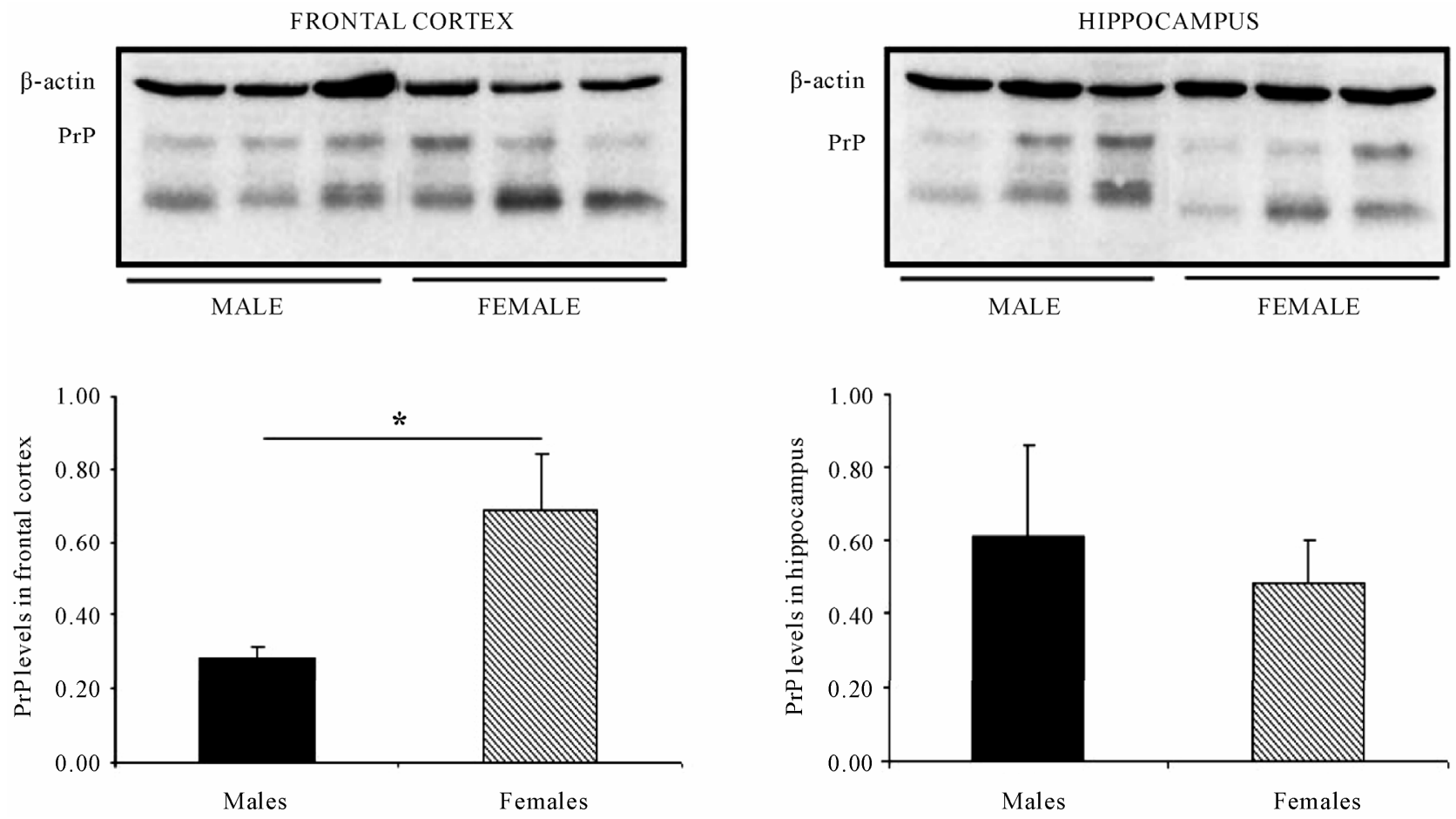

Figure 6. In old mice PrPC levels in the frontal cortex but not in the hippocampus are increased in female mice when compared to male-mice. Representative western blot bands from prefrontal cortex tissues of mice of 3 different ages: young: 6 weeks, adult: 38 weeks and old: 56 weeks. The histograms represent the quantification of the immunochemically reactive bands in the western blot. $p<0.05$. 
the development of the cognitive cerebral areas, inducing an increase in the volume of the CA1 and CA3 pyramidal cells of the hippocampus of male rats [36]. However, in general, the size of the hippocampus is larger in the female of all animals, with the exception of some birds [16].

We observed, as a whole, in the cerebral areas analyzed, that the level of PrPC varies according to the specific structure considered and with regard to the sex (Figures 1-6) [33,34]. Therefore, the data from this study points to a possible dimorphic sexual behaviour of PrPC. It could be a link between the reproductive physiology of rodents and the physiology of PrPC? It is quite probable that the protein is essential in this context.

The fact that the level of PrPC is larger globally in the frontal cortex of female mice as compared to males (Figures 2 and 6) raises the possibility that there is a dimorphic differentiation. One in which, with regard to the hippocampus, the protein increases in level with age, and decreases in the cases of more advanced age, leading to the idea that PrPC may be related to memory processes and, extrapolating on from this, may be associated with the physiopathology of AD.

Another finding which we have come across is that in mice the expression of the non-glycosylated band becomes more pronounced with age, above all in female mice which is in agreement with our previous findings [30]. One can probably say, by extrapolation, and based on previous findings of Velayos et al. [30], that in humans, and more so in women, the greater propensity for Alzheimer's disease and the cognitive symptoms specific to the elderly may be related to the level of non-glycosylated PrPC, all this taken together with the above considerations, with regard to the frontal cortex. On the other hand, the incubation period of the prionopathies is shorter in female mice than in males [37].

The first studies on sexual dimorphism date back to 1976, with the study of song mechanisms in birds [38]. The authors concluded, among other things, that it is the sex hormones which are responsible for the corresponding differentiation. The hormonal influence on sexual differentiation in the central nervous system is well known $[39,40]$. It is well understood how this influence affects the suprachiasmatic nucleus [41], the lateral septum [42], the hippocampus [43], the cerebral cortex [44], the ventromedial hypothalamic nucleus [45], the arcuate nucleus [46], the cerebellar cortex [47], the cerebral amygdala [48], etc. Stress also has a strong influence on the central nervous system, for example, in female rats the posterior cingulate cortex is activated, but not in male rats [49].

All the above points to the great importance hormonal physiology have on the masculine and feminine central nervous system. But as in all biological matters, the facts are multifactorial: genetic factors, hormonal factors, etc. intervene as do factors which are extrinsic to the organism, and specifically, in this case, the role of PrPC which has not yet been studied. For this reason, this study is pioneering, as it shows differences with regard to the level of cellular prion protein in the two sexes in rodents.

\section{REFERENCES}

[1] F. M. P. Krujiver, A. F. Guasti, M. Fodor, E. M. Kraan and D. F. Swaab, "Sex Differences in Androgen Receptors of the Human Mamillary Bodies Are Related to Endocrine Status Rather Than to Sexual Orientation or Transexuallity," Journal of Clinic Endocrinology and Metabolism, Vol. 86, No. 2, 2001, pp. 818-827.

doi:10.1210/jc.86.2.818

[2] F. Loup, E. Tribollet, M. Dbois-Dauphin and J. J. Dreifuss, "Localization of High-Affinity Binding Sites for Oxitocin and Vasopressin in the Human Brain. An Autordiographic Study," Brain Research, Vol. 555, 1991, pp. 220-232. doi:10.1016/0006-8993(91)90345-V

[3] K. Jordan, T. Würstenberg, H. J. Heinze, P. Michael and L. Jäncjke, "Women and Men Exhibit Different Cortical Activation Patterns during Mental Rotation Tasks," Neuropsychologia, Vol. 40, No. 13, 2002, pp. 2397-2408. doi:10.1016/S0028-3932(02)00076-3

[4] B. K. Modney and G. I. Hatton, "Motherhood Modifies Magnocellular Neuronal Interrelationships in Functionally Meaningful Ways," In: N. A. Kasnegor and R. S. Bridges, Eds., Mammalian Parenting, Oxford University Press, New York, 1990, pp. 306-323.

[5] D. F. Swaab, L. J. Gooren and M. A. Hofman, "Brain Research, Gender and Sexual Orientation," Journal of Homosexuality, Vol. 28, No. 3-4, 1995, pp. 283-301. doi:10.1300/J082v28n03 07

[6] P. Vasey and J. Pfaus, "A Sexually Dimorphic Hypothalamic Nucleus in a Macaque Species with Frequent Female-Female Mounting and Same-Sex Partner Preference," Behavior Brain Research, Vol. 157, No. 2, 2004, pp. 265-272. doi:10.1016/j.bbr.2004.07.005

[7] D. F. Swaab and A. Fliers, "Sexually Dimorphic Nucleus in the Human Brain," Science, Vol. 228, 1985, pp. 1112117. doi: $10.1126 /$ science. 3992248

[8] O. Alekseyenko, P. Waters, H. Zhou and M. Baum, "Bilateral Damage to the Sexually Dimorphic Medial Hypothalamic Fos Response to Male Body Odors," Physiology \& Behavior, Vol. 90, No. 2-3, 2006, pp. 438-449. doi:10.1016/i.physbeh.2006.10.005

[9] W. Byne, M. S. Lasco, A. Keruether, A. Shinwri and H. Tobet, "The Interstitial Nuclei of the Human Anterior Hypothalamus: Assesment for Sexual Variation in Volume and Neuronal Size, Density and Number," Brain Research, Vol. 856, No. 1-2, 2000, pp. 254-258. doi:10.1016/S0006-8993(99)02458-0

[10] I. Susana and M. Dulce Madeira, "Estrogen Modulates the Sexually Dimorphic Synaptic Connectivity of the 
Vomeromedial Nucleus," Journal of Comparative Neurology, Vol. 484, 2005, pp. 68-79.

doi:10.1002/cne.20451

[11] A. Guillamón and S. Segovia, "Sez Differences in the Vomeronasal System," Brain Research Bulletin, Vol. 44, No. 4, 1997, pp. 377-382. doi:10.1016/S0361-9230(97)00217-7

[12] X. Protopopescu, H. Pan, M. Altemus, O. Tuescher, M. Polanecsky, B. McEwen, D. Siversweig and E. Stern, "Orbitofrontal Cortex Activity Related to Emotional Processing Changes across the Menstrual Cycle," Proceedings of the National Academy of Sciences (PNAS), Vol. 102, No. 44, 2005, pp. 16060-16065. doi:10.1073/pnas.0502818102

[13] L. Cahill, M. Uncapher, L. Kilptick, M. T. Alkire and J. Turner, "Sex Related Hemispheric Lateralization of Amygdale Function in Emotionally Influenced Memory: An FMRI Invesiation," Learning \& Memory, Vol. 11, No. 3, 2004, pp. 261-266. doi:10.1101/1m.70504

[14] G. Hamann, "Sex Differences in the Responses of Human Amygdale," Neuroscientist, Vol. 11, No. 4, 2005, pp. 288-293. doi:10.1177/1073858404271981

[15] W. C. J. Chung, G. J. de Vies and D. F. Swaab, "Sexual Differentiation of the Bed Nucleus of the Stria Terminalis in Human May Extend into Adulthood," Journal of Neuroscience, Vol. 22, No. 3, 2002, pp. 1027-1033.

[16] K. Petersen and D. Sherry, "No Sex Differences Occurs in Hippocampus, Food-Storing, or Memory for Food Ches in Black-Capped Chickadees," Behavior Brain Research, Vol. 79, 1995, pp. 15-22.

[17] J. M. Goldstein, L. J. Sidman, N. J. Horton, N. Makris, D. N. Kennedy, V. S. Cavines Jr., S. V. Faraone and M. T. Tsuang, "Normal Sexual Dimorphism of the Adult Human Brain Assessed by in Vivo Magnetic Resonance Imaging," Cerebral Cortex, Vol. 11, No. 6, 2001, pp. 490497. doi:10.1093/cercor/11.6.490

[18] E. C. Bell, M. C. Wilson, A. H. Wilman, S. Dave and P. H. Silverstone, "Males and Females Differ in Brain Activation during Congnitive Tasks," Neuroimage, Vol. 30, No. 2, 2006, pp. 529-538.

doi:10.1016/j.neuroimage.2005.09.049

[19] J. Pujol, A. López, N. Cardoner, J. Vallejo, A. Capdevila and T. Paus, "Anatomical Variability of the Anterior Cingulate Gurus and Basic Brain Dimensions of Human Personality," Neuroimage, Vol. 15, No. 4, 2002, pp. 847855. doi:10.1006/nimg.2001.1004

[20] S. M. Breedlove and A. P. Arnold, "Sexually Dimorphic Motor Nucleus in the Lumbar Spinal Cord: Response to Adult Hormone Manipulation, Absence in AndrogenIntensive Rats," Brain Research, Vol. 225, No. 2, 1981, pp. 297-307. doi:10.1016/0006-8993(81)90837-4

[21] P. E. Bendheim, H. R. Brown, R. D. Rudelli, J. Scala, N. L. Goller, G. Y. Wen, et al., "Nearly Ubiquitous Tissue Distribution of the Scrapie Agent Precursor Protein," Neurology, Vol. 42, 1992, pp. 149-156.

[22] J. L. Velayos, A. Irujo, M. Cuadrado-Tejedor, B. Paternain, F. J. Moleres and V. Ferrer, "La Proteína Priónica
Celular en el Sistema Nervioso Central se Mamíferos, Correlatos anatomoclínicos," Neurologia, Vol. 25, No. 4, 2010.

[23] F. Checler and B. Vincent, “Alzheimer's and Prion Diseases: Distinct Pathologies, Common Proteolytic Denominators," Trends in Neruosciences, Vol. 25, No. 12, 2002, pp. 7-12. doi:10.1016/S0166-2236(02)02263-4

[24] T. Voigtländer, S. Klöpel, P. Birner, C. Jaurius, H. Filcker, S. Verghese-Nikolakaki, T. Sklaviadis, M. Gentchev and H. Budka, "Marked Increase of Neuronal Prion Protein immunoreactivity in Alzheimer's Disease and Human Prion Diseases," Acta Neuropatologica, Vol. 101, No. 5, 2001, pp. 417-423.

[25] I. Ferrer, R. Blanco, M. Carmona, B. Puig, R. Ribera, M. J. Rey and T. Ribalta, "Prion Protein Expression in Senile Plaques in Alzheimer's Disease," Acta Neuropathologica, Vol. 101, No. 1, 2001, pp. 49-56.

[26] I. Ferrer, M. Freixas, R. Blanco, M. Caromna and B. Puig, "Selectibe PrP-Like Protein, Doppel Immunoreactivity in Dustrophic Neuritis of Senile Palaques in Alzheimer's Disease," Neuropathology and Applied Neurobiology, Vol. 30, No. 4, 2004, pp. 329-337. doi:10.1111/j.1365-2990.2003.00534.x

[27] B. H. Kim, H. G. Lee, J. K. Choi, J. I. Kim, E. K. Choi, R. I. Carp and Y. S. Kim, "The Cellular Prion Protein (PrPC) Prevents Apoptotic Neuronal Cell Death and Mitocondrial Disfunction Induced by Serum Deprivation," Molecular Brain Research, Vol. 124, 2004, pp. 40-50. doi:10.1016/j.molbrainres.2004.02.005

[28] R. Veerhuis, R. S. Boshuizen and A. Familian, "Amyloid Associated Proteins in Alzheimer's and Prion Diseases," Current Drug Targets-CNS \& Neurological Disorders, Vol. 4, No. 3, 2005, pp. 235-248. doi:10.2174/1568007054038184

[29] P. Rezaie, C. C. Pontikis, L. Hudson, N. J. Cairns and P. L. Lantos, "Expression of Cellular Prion Protein in the Frontal and Occitpital Lobe in Allzheimer's Disease, Diffuse Lewy Body Disease, and in Normal Brain: An immunohistochemical Study," Journal of Histochemistry Cytochemistry, Vol. 53, No. 8, 2005, pp. 929-940. doi:10.1369/jhc.4A6551.2005

[30] J. L. Velayos, A. Irujo, M. Cuadrado-Tejedor, B. Paternain, F. J. Moleres and V. Ferrer, "The Cellular Prion Protein and Its Role in Alzheimer's Disease," Prion, Vol. 3, No. 2, 2009, pp. 110-117. doi:10.4161/pri.3.2.9135

[31] F. P. M. Krujiver, R. Balesar, E. Esplia, A. M. Unga, A. Unmehopa and D. F. Swaab, "Estrogen Receptor Distribution in the Human Hypothalamus in Relation to Sex and Endocrine Status," Journal of Comparative Neurology, Vol. 454, No. 2, 2002, pp. 115-139. doi:10.1002/cne.10416

[32] N. López Moratalla, "Cerebro de Mujer y Cerebro de varón," Instituto de Ciencias para la Familia, Universidad de Navarra, 2008.

[33] R. A. Gorski, J. H. Gordon, J. E. Shryne and A. M. Southam, "Evidence for a Morphological Sex Difference within the Medial Preoptic Area of the Rat Brain," Brain 
Research, Vol. 148, 1978, pp. 333-346. doi:10.1016/0006-8993(78)90723-0

[34] R. A. Gorski, R. E. Haslan, C. O. Jacobson, J. E. Shryne and A. M. Soutam, "Evidence for the Existence of a Sexually Dimorphic Nucleus in the Preoptic Area of the Rat," Journal of Comparative Neurology, Vol. 198, 1980, pp. 529-539. doi:10.1002/cne.901930214

[35] S. Ito, S. Murakami, K. Yamanouchi and Y. Arai, "Prenatal Androgen Exposure, Preoptic Area and Reproductive Functions in the Female Rat," Brain \& Development, Vol. 8, 1986, pp. 463-468.

[36] C. Isgor and D. R. Sengelaub, "Prenatal Gonadal Steroids Affect Adult Spatial Behaviour, CA1 and CA3 Pyramidal Cell Morphology in Rats," Hormones and Behavior, Vol. 34, No. 2, 1998, pp. 183-198. doi:10.1006/hbeh.1998.1477

[37] C. Loeuillet, P. Y. Boelle, C. Lemaire-Vieille, M. Baldazza, P. Naquet, P. Chambon, M. F. Cesbron-Delauw, J. Valleron and J. Y. Cesbron, "Sex Effect in Mouse and Human Prion Disease," Journal of Infectious Disease, Vol. 202, No. 4, 2010, pp. 648-654.

[38] F. Nottebom and A. P. Arnold, "Sexual Dimorphism in Vocal Control Areas of the Songbird Brain," Science, Vol. 194, No. 4261, 1976, pp. 211-213. doi:10.1126/science.959852

[39] G. W. Harris, "Hormonal Differentiation of the Developing Central Nervous System with Respect to Patterns of Endocrine Function," Philosophical Transactions of the Royal Society B, Vol. 259, No. 828, 1970, pp. 165-176. doi:10.1098/rstb.1970.0056

[40] G. Raisman and P. M. Field, "Secual Dimorphism in the Neuropil of the Preoptic Area of the Rat and Its Dependence on Neonatal Androgen," Brain Research, Vol. 54, 1973, pp. 1-29. doi:10.1016/0006-8993(73)90030-9

[41] F. H. Güldner, "Sexual Dimorphism of Axo-Spines Synapses and Postsynatic Density Material in the Suprachiasmatic Nucleus of the Rat," Nuroscience Letters, Vol. 28, No. 2, 1982, pp. 145-150. doi:10.1016/0304-3940(82)90143-4

[42] G. J. De Vries and A. A. Sluiter, "The Influence of Androgens on the DEVELOPMEnt of a Sex Difference in the Vasopressinergic Innervation of the Rat Lateral Septum," Developmental Brain Research, Vol. 8, No. 2-3, 1983, pp. 377-380.

doi:10.1016/0165-3806(83)90019-6

[43] E. Gould, A. Westlind-Danielsson, M. Frankfurt and B. S. McEwen, "Sex Differences and Thyroid Hormone Sensitivity of Hippocampal Pyramidal Cells," Journal of Neuroscience, Vol. 10, 1990, pp. 996-1003.

[44] J. M. Juraska, "Sex Differences in 'Cognitive' Regions of the Rat Brain," Psyconeuroendocrinology, Vol. 16, 1991, pp. 105-119. doi:10.1016/0306-4530(91)90073-3

[45] A. Matsumoto, "Synaptogenic Action of Sex Steroids in Developing and Adult Neuroendocrine Brain," Psyconeuroendocrinology, Vol. 16, 1991, pp. 25-40. doi:10.1016/0306-4530(91)90069-6

[46] L. M. García-Segura, J. A. Chowen, A. Párducz and F. Naftolin, "Gonadal Hormones as Promoters of Structural Synaptic Plasticity: Cellular Mechanisms," Progress in Neurobiology, Vol. 44, No. 3, 1994, pp. 279-307. doi:10.1016/0301-0082(94)90042-6

[47] H. Sakamoto, Y. Mezaki, H. Shuikimi, K. Ukena and K. Tsutsuy, "Dendritic Growth and Spine Formation in Response to Estrogfen in Developing Purkije Cell," Endocrinology, Vol. 144, No. 10, 2003, pp. 4466-4477. doi:10.1210/en.2003-0307

[48] B. M. Cooke, M. R. Stokas and C. S. Woolley, "Morphological Sex Differences Nad Laterality in the Prepubertal Medial Amygdale," Journal of Comparative Neurology, Vol. 501, No. 6, 2007, pp. 904-915. doi:10.1002/cne.21281

[49] M. K. Park, T. A. Hoang, J. D. Belluzzi and F. M. Leslie, "Gender Specific Effect of Neonatal Handling on Stress Reactivity of Adolescent Rats," Journal of Neuroendocrinology, Vol. 15, No. 3, 2003, pp. 289-295. doi:10.1046/j.1365-2826.2003.01010.x 